\title{
Paradoxical Reduction in Tissue Hydration with Weight Gain in Neonatal Rabbit Pups
}

\author{
DAVID M. COULTER." AND MARY ELLEN AVERY
}

Deparment of Pediatrics, Harvard Medical School, Boston. Massachusetts, USA

\begin{abstract}
Summary
We measured body hydration of healthy, term rabbit pups at birth and $72 \mathrm{hr}$ of age. In addition, we measured hydration of individual tissues: skin, skeletal muscle, liver, and brain. At birth. the hydration of lean body mass, skin, and skeletal muscle, expressed as cc water per g fat-free dry weight (FFDW) was inversely proportional to birth weight. Low birth weight animals were significantly better hydrated than their larger littermates.

During the first $72 \mathrm{hr}$ of life, the nursing pups gained an average $31.3 \%$ of birth weight. Simultaneously, lean body hydration decreased by $23 \%$ ( 5.48 to $4.86 \mathrm{cc} / \mathrm{g}$ FFDW). The hydration change varied substantially among organs. The greatest loss occurred in skin $(24 \%)$. Skeletal muscle lost $5.8 \%$, and the brain lost $3.1 \%$.

When hydration at $72 \mathrm{hr}$ was compared to weight gain and by inference fluid intake, a paradoxical result was obtained. Lean body, skin, and skeletal muscle hydration was inversely related to weight gain. The animals that gained the most weight retained the least water. In contrast, the hydration of brain and liver was significantly higher in animals that gained the most weight.

We conclude that the newborn rabbit is endowed with a reservoir of fluid at birth, predominantly stored in skin and skeletal muscle. The rate of release of this store depends on fluid intake. It is rapidly lost if ample fluid intake is provided. In conditions of restricted fluid intake, the release is substantially slower.
\end{abstract}

\section{Speculation}

At least two processes regulate tissue hydration in the newborn rabbit. The first, a function of growth, is responsible for the progressive accretion of intracellular water during gestation and postnatal development. It is illustrated by the increase in tissue hydration of brain and liver in well-nourished pups during the first $72 \mathrm{hr}$ of life.

The second process may be under hormonal regulation on a time scale of hr to days. It accounts for the relatively high level of tissue hydration at birth, and provides a supply of water and sodium to maintain plasma volume during the first days of life, thereby preventing dehydration during this period of variable fluid intake.

The fetus undergoes a progressive decrease in total body hydration during gestation $(2,17,24,30,37,38)$, with alterations in partitioning of water: the intracellular fluid (ICF) increases and extracellular fluid (ECF) falls (1, 6, 11, 14, 15, 27). These processes continue in infancy and childhood until adult levels are attained $(3,38)$.

In the first days of extrauterine life, acute changes are superimposed on the long-term trends. Starved infants lose 7 to $11 \%$ of total body water in the first $72 \mathrm{hr}$ of life $(13,30)$. The rise in ICF, occurring throughout fetal life. is temporarily reversed, and the newborn loses ICF for the first $72 \mathrm{hr}$ before the level stabilizes and again resumes its increase (26). These statements describe water balance in groups of neonates. However, individual infants may vary from this pattern. Operative delivery and perinatal events such as birth asphyxia may alter fluid and electrolyte balance in the neonate.

The tissue sources of the neonatal water loss have not been fully defined. Brain loses small amounts in newborn rodents (12. 18 . 33. 34). One study described small water losses from rat skeletal muscle (20) whereas another found no muscle water loss at all in human newborns (28).

We undertook the current study in newborn rabbits to identify the tissue sources of neonatal water loss and to determine their relative contributions to total body water loss.

\section{MATERIALS ANI) METHODS}

Healthy timed gestation New Zealand White rabbit does were obtained from local commercial breeders. They were housed in standard cages with hay-filled nesting boxes and were fed Purina rabbit chow. We observed them frequently to determine the time of parturition.

As soon as possible after delivery, usually within 2 to $4 \mathrm{hr}$. the pups were weighed and marked. and one-half of the litter was sacrificed for initial hydration measurements. The remaining pups were returned to the mother who cared for them until $72 \mathrm{hr}$ of age when they were reweighed and sacrificed. Some litlers were salerificed in toto at birth or at $72 \mathrm{hr}$.

The pups were killed by decapitation and exsanguinated. A piece of dorsal skin was immediately removed. weighed. and minced with scissors. Then, in rapid sequence. both quadriceps femoris muscles, the liver, and the forebrain were removed. weighed immediately, and minced. The remainder of the carcass was homogenized in a blender. The specimens were air-dried in a $93^{\circ} \mathrm{C}$ oven to constant weight. The tissue samples and an aliquot of the carcass specimen were then repeatedly extracted to constant weight with petroleum ether to eliminate fat. Fat and water content were calculated from differences in weight.

Groups were compared by Fisher's exact $t$ test. and linear regressions were calculated using the method of least squares.

\section{RESULTS}

The mean birth weight of the term rabbit pups was $52.1 \mathrm{~g}$ (range. 29.5 to $74.5 \mathrm{~g}$ ). Body fat and water composition at birth were direct functions of birth weight. Total body fat increased linearly with increasing birth weight $(n=23 ; r=0.920 ; P<$ $0.0001)$. In contrast, the hydration of lean body mass, expressed as $\mathrm{ml}$ of water per $\mathrm{g}$ fat-free dry weight was an inverse function of birth weight (Fig. 1. $r=0.570 ; P<0.005)$. The hydration of fatfree skeletal muscle $(n=57: r=-0.435 ; P<0.01)$ and skin $(n$ $=37: r=-0.561: P<0.001)$ similarly decreased with increasing birth weight. Brain and liver hydration were unrelated to birth weight.

During the first $72 \mathrm{hr}$ of life. the mean decrease in lean body hydration was $11.6 \%$. Figure 2 compares lean body and individual 


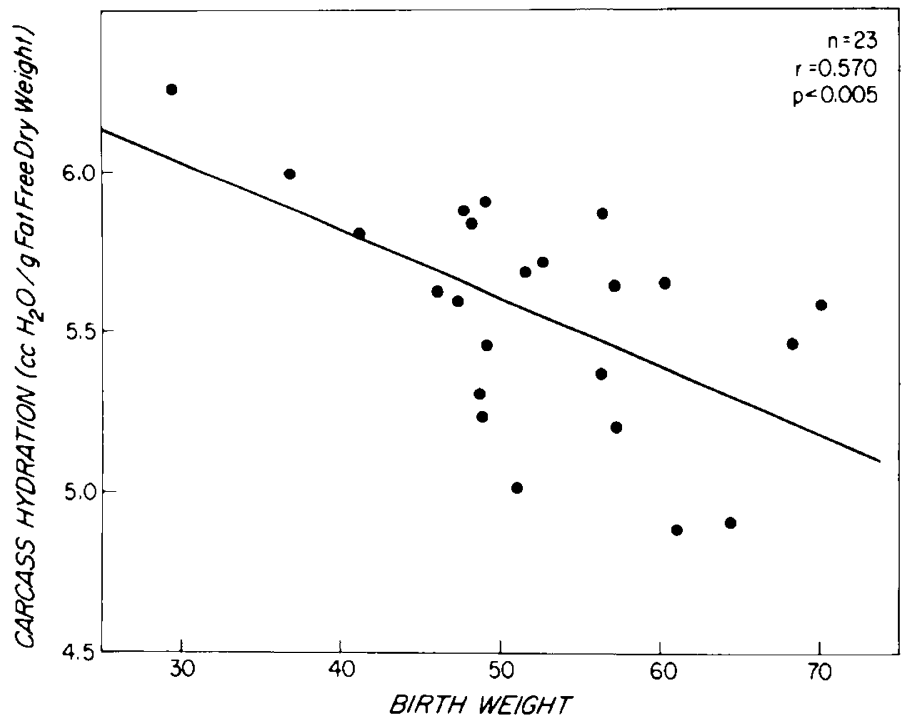

Fig. 1. The relationship between body hydration and birth weight at term.

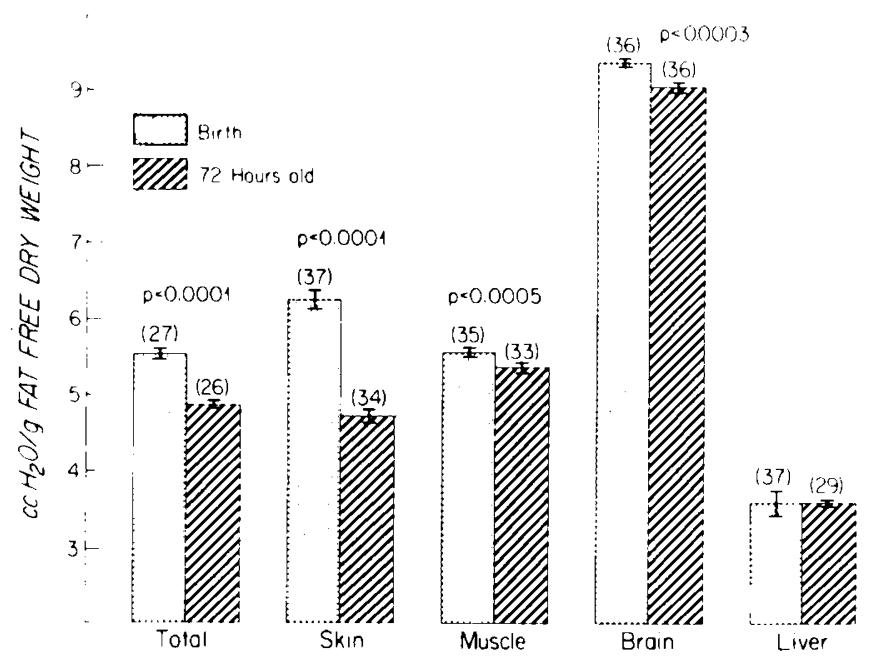

Fig. 2. The hydration of lean body mass and of skin, skeletal muscle, brain. and liver at birth and $72 \mathrm{hr}$ of age. Bars. S.E. Numbers in parentheses, number of animals in each group.

tissue hydration at birth and $72 \mathrm{hr}$ of age. The extent of water loss varied among individual tissues. The greatest loss occurred in skin $(24.2 \%)$ followed by skeletal muscle $(5.8 \%)$ and brain $(3.1 \%)$. Liver hydration did not change when the $72 \mathrm{hr}$ group was considered as a whole.

The pups gained an average $31.3 \%$ of their birth weight (range, $19 \%$ loss to $74 \%$ gain). Weight gain varied considerably among litters. Some appeared very well cared for by the does. The pups were clean. and the nest was well made and well cared for. In such litters, particularly those with fewer than 8 pups, weight gain was uniformly high $(40$ to $60 \%$ of birth weight). Other litters appeared neglected by the does. Little effort seemed to have been expended on building or maintaining the nest. The pups became crusted with dried urine and were malodorous, and they lost weight. Variable weight gain also occurred in some of the larger litters which seemed well cared for. In one litter of 11 pups, $72-\mathrm{hr}$ weight changed varied from an $8 \%$ loss to a 50$)^{\prime \prime}$, gain.

At the time of sacrifice, the animals who lost weight or gained very little were uniformly deficient in subcutaneous and hepatic fat. Their gastrointestinal tracts contained little or no milk. In contrast, the gastrointestinal tracts of their more successful littermates were grossly distended with milk. The total body fat content at $72 \mathrm{hr}$ was directly related to weight gain $(r=0.872: n=28: P$ $\left.<10^{\circ}\right)$. These observations suggest that weight gain is a reflection of milk intake and that low weight gain can most probably be ascribed to low intake of water and calories.

When 72 -hr-old pups gaining more than $30 \mathrm{~g}$ were compared to those gaining less than $30 \mathrm{~g}$ (Fig. 3), significant differences are apparent. The anticipated increase in tissue hydration with greater weight gain was seen in brain and liver. However, lean body, skin. and skeletal muscle hydration had an opposite relationship. The animals that gained the most weight and by inference had the largest fluid intake retained the least water. Linear regression analysis further emphasizes the highly significant differences between hydration changes in brain (Fig. 4) and in lean body (Fig. 5 ) or skin (Fig. 6). Changes in skeletal muscle paralleled those in the total body and skin $(n=31: r=-0.648: P<0.0005)$.

At the end of the 72-hr time period. four of the pups were clinically dehydrated. Their skin turgor was poor, and they were hypoactive or moribund. Table I shows the tissue hydration of these animals and compares them to groups that gained greater than and less than $30 \%$ of birth weight. They are also plotted on the regression curves as filled circles. As a group, they were less well hydrated than either weight gain group. but were nearer in

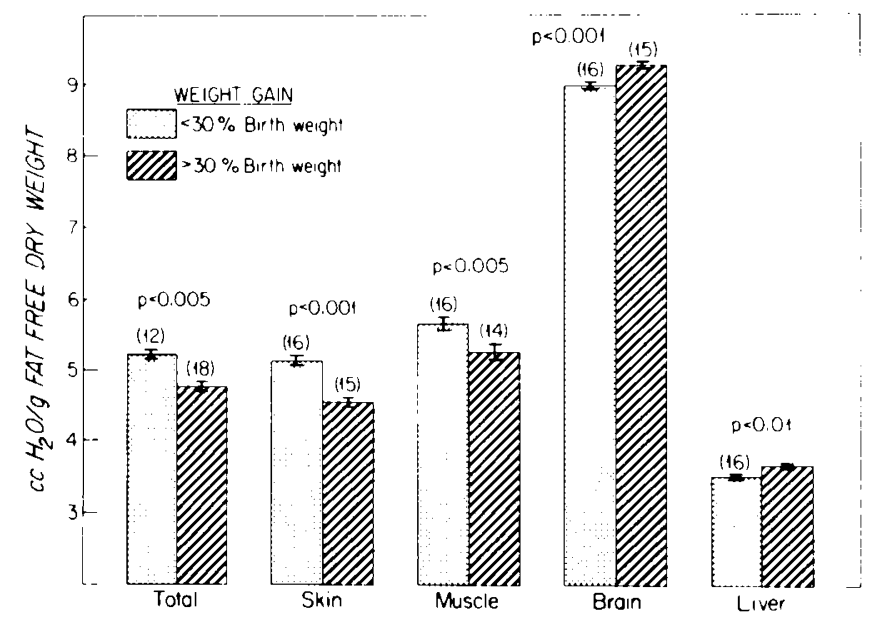

Fig. 3. Comparison of total body hydration and that of individual organs in animals gaining more than $30 \%$; of hirth weight with those gaining less than $30^{\prime \prime}$. Bars, S.E. Numbers in parentheses, number of animals in each group.

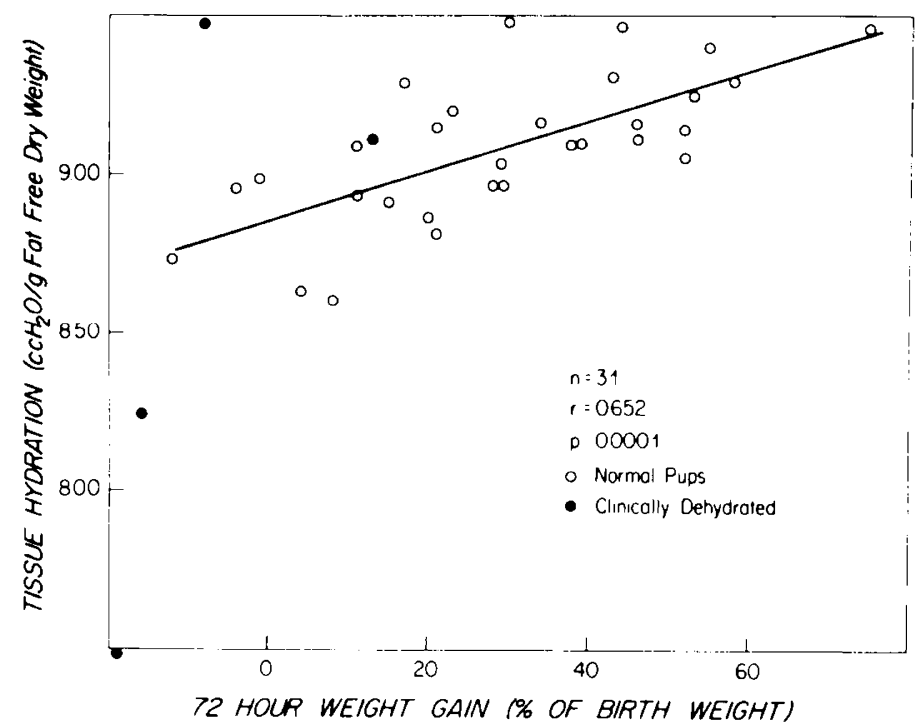

Fig. 4. The relationship between body weight gain and brain hydration at $72 \mathrm{hr}$ of age. Regression calculated for normal pups only. 
water composition to the high weight gain group rather than to the low weight gain group. the pups who were more similar in weight gain to the dehydrated animals.

\section{DISC USSION}

The hydration of the newborn has been related to intrauterine growth. Widdowson (35) compared the largest and smallest piglets in three litters and found that the smallest contained a significantly

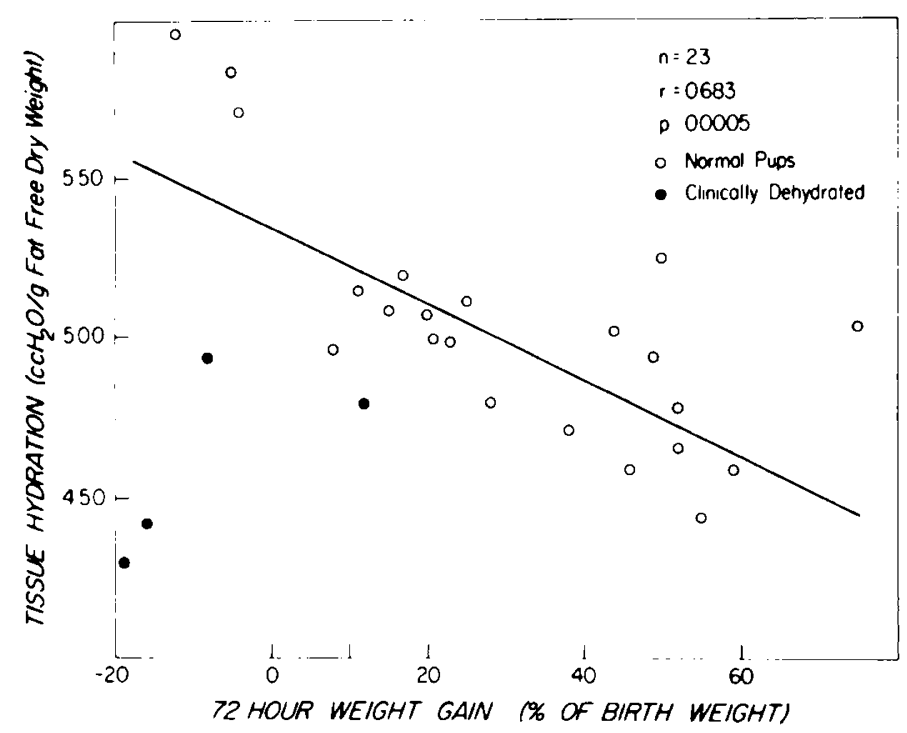

lig. 5. The relationship between body weight gain and hydration of lean hody mass at $72 \mathrm{hr}$ of age. Regression calculated for normal pups only.

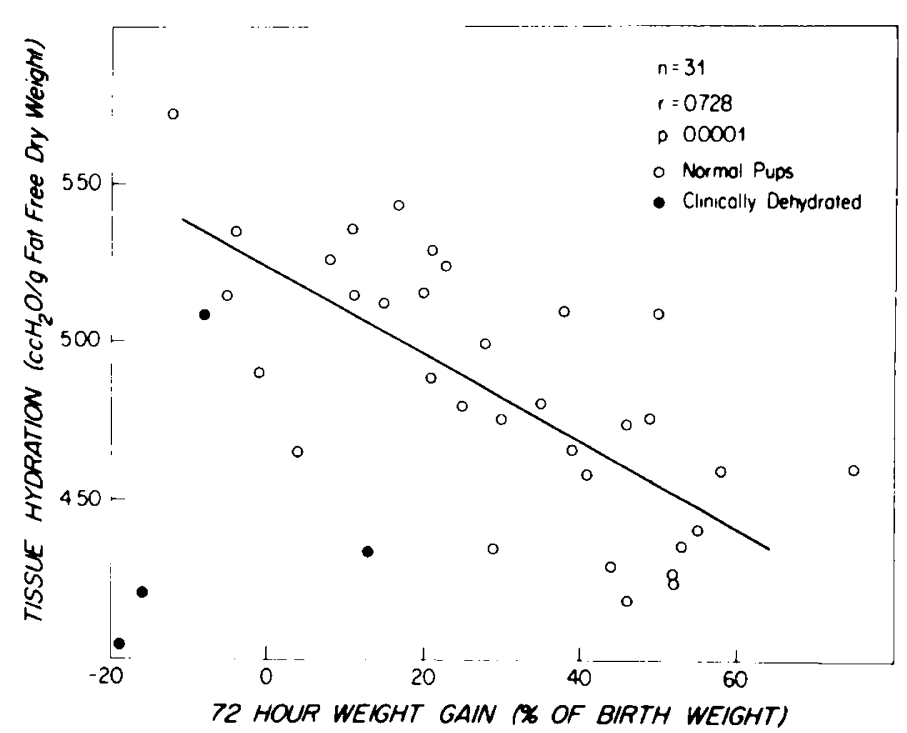

Fig. 6 . The relationship between body weight gain and skin hydration at $72 \mathrm{hr}$ of age. Regression calculated for normal pups only. greater percentage of water than the largest. With correction for body fat. the same trend is found. Subsequent dessication studies in rats (22) and tracer experiments in human infants (5.6) confirm that groups of growth-retarded infants have significantly greater hydration of lean body mass than appropriately grown controls.

We have extended these observations to show that lean body hydration at term in the rabbit is an inverse. linear function of fat-free body weight. One possible explanation of this observation would be inadequate removal of body fat. Adipose tissue has virtually no water content, and deposition of fat in the fetus is associated with decreasing total body water (36). Failure to remove fat completely would lead to underestimation of lean body and organ hydration. However, our measurements of body fat composition of the newborn rabbit are consistent with one other study (23) and slightly higher than two previously reported results (3I. 35). Furthermore, we found clear correlations between birth weight and fat content and between 72 -hr weight gain and body fat content. These results indicate that we obtained quantitative removal of body fat and make it unlikely that our hydration measurements are due to an inadequate removal of body fat.

The water content of the fetus falls progressively during gestation. Very early human fetuses weighing less than $20 \mathrm{~g}$ are composed of 91 to $95 \%$ water (36). At term, the water content has fallen to $82 \%$ of fat-free body weight (2.36). similar to the $83.4 \%$ we have measured in the rabbit. This trend persists during infancy and childhood until the adult value of $72^{\prime \prime}$; of total body weight is attained $(15,37)$.

The smooth progress of antenatal changes in body water content is interrupted at birth by rapid fluid shifts during the transition from intrauterine to extrauterine life. Breast fed. term. human infants lose $7 \%$ of total body water during the first $72 \mathrm{hr}$ of life (30), whereas starved prematures lose $11 \%$ in this period (13). This persistent fluid and electrolyte loss in the absence of intake has been ascribed to renal immaturity (19). However, subsequent work has shown that healthy newborns are capable of antidiuretic hormone and renal responses to moderate solute and volume loading (13, 25).

The water losses observed in starved infants persist if fluid is administered. Hansen and Smith (19) showed that when water was provided to starved. term infants. urinary water losses increased accordingly. Similarly, rates of total body water and weight losses are similar in starved and bottle-fed infants (26). In a group of prematures denied fluid for $72 \mathrm{hr}$, urine output peaked during the second day of fluid deprivation. These infants showed no clinical evidence of dehydration (4). During this time, plasma osmolarity and sodium remained essentially unchanged (9). Thus, water and sodium are mobilized and excreted by the neonate even if intake is low.

There are clear differences between rabbits and human neonates in the degree of maturity at birth. In other respects. important similarities exist. In utero, both species are supplied with adequate fluid and electrolyte intake by the placenta and amniotic fluid and are protected against fluid losses by the uterine environment. Postnatally, in the normal situation, they are dependent upon the availability of milk to meet their fluid and electrolyte needs and lose substantial quantities of water to the environment.

In the current study, term nursing rabbit pups lost an average of $11.6 \%$ of total body water during the first $72 \mathrm{hr}$ of life, a quantity comparable to measured losses in human infants. How-

Table 1. A comparison of the group of clinically dehydrated animals with those gaining less than 30\% of birth weight and more than $30 \%$ of birth weight

Tissue hydration (cc/g fat-free dry wt)

Dehydrated

Dehydrated
Normal

' Numbers in parentheses, S.E.
Mean wt gain (" of birth weight)

$$
-7.5
$$

15

50
Total

$4.61(0.15)$

$5.24(0.11)$

$4.80(0.08)$
Skin

$4.42(0.46)$

$5.11(0.08)$

$4.56(0.07)$
Muscle

$5.37(0.50)$

$5.66(0.09)$

$5.26(0.10)$
Brain

8.27 (1.44)

$8.99(0.06)$

$9.30(0.05)$ 
er, in contrast to the human babies who are also losing weight this time, the rabbits gained relatively large amounts of weight. hen we analyzed our results as a function of weight gain. and, inference, fluid intake, an unexpected result emerged. The tent of neonatal fluid loss was inversely proportional to weight in. The animals with the greatest tluid intake lost the largest oportion of fat free tissue hydration.

The water loss occurred to different degrees in different tissues. te greatest losses occurred in skin (24.2\%) (to some extent the sult of surface drying) and skeletal muscle $(5.8 \%)$. Together ese tissues comprise over $40 \%$ of body weight and $46 \%$ of body tter in human newborns (37). Therefore, they are the major urce of water loss. The brain of the human contributes $13 \%$ to al body weight and $17 \%$, to total body water (37). In contrast, z brain is only $2.3 " ;$ of body weight in the newborn rabbit (22). dits contribution to total water flux is small. Rabbit brain loses $" \Rightarrow$ of its water content at $72 \mathrm{hr}$. comparable to previously orted values in rats $(12,34)$, mice $(33)$, and rabbits $(18)$. There 2 no similar studies in humans. However. intracranial volume $s$ been calculated from head measurements in human infants at hr of age and has shown a 7.5 to $9^{\prime \prime}$ ' decrease at this age (39). lese larger changes in intracranial volume of human infants ty be explained by alterations in the volume of cerebrospinal id. Our methods only assessed tissue hydration.

Concomitant with the decrease in lean body hydration during al development is a change in partitioning of water between the racellular and extracellular compartments. ICF gradually inases, and E( F falls (1. 6, 11. 14, 15, 27). This process also atinues during infancy and childhood $(3,38)$.

Work by Maclaurin (26) in the human identified the IC $\mathrm{IF}$ as the arce of neonatal water losses. He measured thiocyanate space 1 index of $\mathrm{E}(\mathrm{F})$. D.O space (an index of total body water). ight. blood volume. and mean corpuscular hemoglobin concention in a group of human infants during the immediate neonatal riod. Total body water fell during the first $72 \mathrm{hr}$ and then bilized and began to rise by day 5 . Parallel changes occurred in : intracellular water. ECF rose slightly. and plasma volume nained stable. The decrease in intracellular fluid was reflected red cell shrinkage identified by a rise in mean corpuscular moglobin. Others have documented significant decreases of cell ter during the first day of life $(6,7)$. The development of leg ima in starved premature infants during the first day of life (32) $y$ be another indicator of this fluid shift. Presumably, these ants are able to mobilize fluid from the ICF to the ECF. vement into the vascular space. however, may be limited by - plasma oncotic pressure. a result of their low plasma protein icentration (29).

In Maclaurin's study (26). plasma osmolality did not change spite ongoing urine sodium losses, a net movement of water out the intracellular space and slight expansion of the intracellular cee. Davis et al. (9) obtained similar results. Thus, sodium ompanied the water shift. The source of this sodium is probably intracellular space. Hazlewood et al. (21) summarized animal a indicating that intracellular sodium and chloride content eed that of potassium at birth and that these relationships erse during the first wk of life. They confirmed these results in whorn rats, documenting a ten-fold decrease in intracellular lium and a concomitant decrease in tissue hydration.

Ne have demonstrated that these neonatal tluid shifts correlate $h$ postnatal weight gain and fluid intake. Total lean body Jration and the water content of fat-free skin and skeletal scle fall in inverse proportion to fluid intake. Low tluid intake ults in retention of cell water wheras higher intakes permit re rapid release. It would thus appear that neonatal intracellular ter and sodium content are regulated by a mechanism which ponds to fluid intake.

Jther factors are also important. The skin. for example. appears ist and soft on day one and then dries and darkens in color. t $t$ the water loss from the skin is probably due to dessication he external, keratinized layers of cells after exposure to air. We bt that this process is regulated by an homeostatic mechanism.
Changes in brain hydration differ from those of skin or skeletal muscle. Water content of brain at $72 \mathrm{hr}$ of age was directly correlated with weight gain. In animals which gained over $30 \%$ of birth weight, brain water was identical to that of animals at birth. Brains of animals gaining less than $30 \%$ of birth weight contained less water than those of newborns $(P<0.0001)$ or their larger littermates $(P<0.001)$. Similarly, liver hydration was greater in animals who gained more than $30 \%$ of birthweight. It would appear that the regulators of brain and liver hydration differ from those regulating skin and skeletal muscle water, the main determinants of total body water.

Starved human neonates lose 7 to $11 \%$ of total body water in the first $72 \mathrm{hr}$ of life $(13,39)$, yet show no clinical signs of dehydration save for moderate oliguria (4). Older infants with a similar degree of acute water loss are usually clinically dehydrated and sick. A similar observation in newborn pigs has been made by Gentz et al. (16). They were investigating the metabolic effects of starvation and noted that plasma volume was well maintained for $96 \mathrm{hr}$ in piglets starved from birth. Those allowed access to feedings for $24 \mathrm{hr}$ or longer before starvation showed significant decreases of plasma volume within the first $48 \mathrm{hr}$ of starvation. We would postulate that the latter group of animals had already mobilized a substantial portion of its water reserves during the period of feeding and was thus less well prepared for a period of fluid deprivation.

It appears that cell water and sodium content can be controlled in the perinatal period. There is an intracellular reservoir of tluid and electrolyte at birth. This fluid is released rapidly if sufficient lluid intake is available. In the absence of adequate intake, it is released more slowly. perhaps as a means to protect the circulating blood volume and thereby to maintain tissue perfusion. Despite measured "dehydration" of body tissues. clinical signs of dehydration usually do not become evident. However. with very low intake. neonatal water losses may ultimately exceed the compensatory capacity of tissue reserves. We found four of the pups to be clinically dehydrated. and their tissue hydration to be less than that of their healthy counterparts. It is of interest that their tissue hydration more closely resembled that of pups with large weight gains. rather than pups who had similarly low gains or losses.

There is an interesting maternal parallel to gestational and neonatal fluid shifts. During gestation, there is a significant expansion of maternal body fluid. often associated with the onset of clinical edema. This change is promptly reversed in the early postpartum period $(8)$. Inasmuch as mother and fetus share a similar hormonal milieu, the search for the hormonal mediators of these fluid shifts might profitably be pursued within the group of hormones that are elevated in late pregnancy and that fall during the immediate postnatal period.

\section{REFH:REN(ES ANI) NOTISS}

1. Adolph. L. F Ontogeny of volume regulations in embryonic extratellular fluids. Q. Rev. Biol.. 4:: I (1967).

2. Apte. S. W. and Jyengar. L..: (omposition of the human foetus. Br. J. Nutr.. ?" $315(1972)$.

3. Assali. N. S., Dellaven. J. ( ... and Barrett. ( . T.: Disorders of water. electrolyle, and acid-hase halance. In: N S Assali: Pathophysiology of (iestation. Vol. 3. (Academac Press, Inc. Neu Yorh. 1972).

4. Beard. A. (;.. Panos. T. (.. Burroughs. J. (.. Marasigan. B. V.. and Oztalay, A. G.: Perinatal stress and the premature infant: 1. Fffect of thuid and calorie deprivation. J. Pediatr. 0.3: 361 (1963).

5. Cassady. ( $i$. Bromide space studes in infants of low birth weight. Pediatr. Res.. 4: $14(1970)$.

6. Cassady. ( $i$. and Milstead, R. R.: Antipyrine space studies and cell water estimates in intants of low hirth veight. Pediatr. Res.. 5: 673 (1972)

7. (heek. D. B.: Extracellular wolume: its structure and measurement and the intluence of age and discase. J. Pediatr.. 5.5: 103 (1961).

X. (hesley. I). 1..: Disorders of the kidney. lluids, and electrolytes. In: N. S. Assalt: The Pathophysiology of (iestation. Vol. I. p. 355 (Academic Press. Inc.. New York. 1972).

9. Davis. J. A. Harsey, D) R. and Stevens. J. F.: Osmolality as a measure of dehydratwon in the noenatal period. Arch. Dis. ( hild. 41 : $44 \times(1966)$

10. Davison. A $\mathrm{N}$ : Myelination as a vulnerable period in hrain development. Br. Med. Bull. :2: 40)(1966)

11. Dickersm. J. W. T. and Widdowson. F. M : (hemical changes in skeletal muscle during development. Biochem, J.. 7 : 247 (1960)). 
12. Donaldoen. H. H. and Hatit, $\mathrm{S}$ : On the weight of the parts of the hrain and on the percentage of water in them according to brain weight and to age in albino and in wild Norway rats. J. (Comp. Neurol. 5.3: 26,3 (1931).

13. Fisher. 1) A. Pvle. H. R. Porter. J. ( . et al.: (control of water balance in the newborn. Am. J. Dis. (hild. /16: 137 (1963)

14. Hexner. 1. B.. Wilde. W. S.. Procior. N. K. (iwie. D). B.. Vonhurgh. (i. H.. and Hellman. L.. M.: The entimation of extracellular and total hody water in the

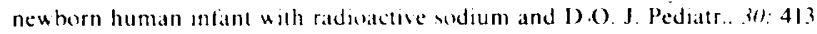
(1947).

15. Friss-Hansen. B.: Bods water compartments in children changes during growth and related changes in body composition. Pediatrics. $25: 169(1961)$.

16. Gents. J.. Bengturon. (i.. Makkarainen. J.. Hellstrom. R.. and Perrson. B.: Metaholic effects of starsation during the neonatal period in the piglet. Am. J. Physiol. 2/8: $022(197(1)$

17. Givens. M. H.. and Macy. I. (i.. ('hemical composition of the human fetus. J. Biol. (hem.. I1): 7 (1933)

Ix. (iraves, J., and Himmuich. H. L.. Age and the water content of rahbit bratin pars Am. J Physiol. 1.80) 2015 (1458)

19. Hansen. J. D) 1.., and Smuth. ( A. The effects of withholding tluid in the immediate portnatal period. Pediatrics. $12: 44(1453)$.

20. Hatewood. (C... and Nichols. B. L.: ( hanges in muscle sodium. postassium. chloride. water and woltage during maturation in the rat: an experimental and theorelucal suds Johns Horphin Med J. I25: 119(1969).

21. Hasleword. (. F. Nichoh, B. 1... (hang. I). (... and Brown. B.: On the state of water in developing muscle: a study of the major phase of ordered water in sheletal muscle and its relationship to sodium concentration. Johns Hopkins Med. J. ISY: $117(1971)$.

22. Hohenauer. $1 .$. and $(O h . W .:$ Body composition in experimental intrauterine growth retardation in the rat. J. Nutr.. $49: 23(1969)$

23. Hudson. D) ( $i$, and Hall. D): (irouth of adipose tissue in the fetal rabbit. Biol. Neonate. 2-: $71(1975)$.

24. Ioh. V.. and Suanown. W. W.: Mineral grouth of the human fetus. Am. J. Dis. ('hild.. $4^{-7}: 312(1934)$

25. 1.eake. R. D.. Stathauddin. S.. Trugstad. (. W.. Fu. P.. and Oh. W'.: The effects of large volume intratenous huid infusion on neonatal renal function. $J$.

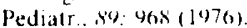

26. Maclaurin. J. ( $:$ ( hanges in body water distribution during the first two weeks of life. Arch. Dis. ('hild.. Al: $286(1960)$

27. Mccance, R. A.. and Widdow son. E. M. The chemical structure of the human bodv. Q. J Exp. Phisiol (iogn. Med. Sit. 11: I (1956).

(opyright (i) 1980 International Pediatric Research Foundation. Inc. (0) $31-3998 / 80) / 1410-11122 \$(1) 2.00 / 0$ 2x. Nichols. B. I... Rudolph. A. J.. and Hazlewood. (. I.: The role of muscle extrarenal electrolyte metaholism in the newborn Johns Hopkins Med. J.. I $212(1972)$.

24. Pincus. J. B.. (ittelman. I. F.. Saito. M., and Sobel. A. F. A study of plas values of sodium. potassium. chloride. carbon dioxide. carbon dioxide tens sugar. urea. and the protein hase binding power. pll. and hematocrit prematures on the first day of hife. Pediatrics, /s: 34 (1956).

30. Smith. (. A.: Physiology of the Newborn Infant. Ed. 3. p. 339 (Charles Thomas. Springtield. 1959).

31. Spras. ( . M.. and Widdowson, E. M.: The effect of growth and development the composition of mammals. Br. J. Nutr.. f: 332 (1951).

32. Sutherland. J. M.. Oppe. T. E.. L.ucey. J. F.. and Smith. (. A.: Leg volu changes observed in hyaline membrane disease. Am. J. Dis. (hild.. Y, $(1959)$.

33. Uxman. L. L.. and Rumley, M. K.: (hanges in the composition of the develop mouse brain during early myelinization. J. Neurochem.. i: 170 (1958).

34. Vernadiakis, A.. and Wordbury. D. M.: Electrolyte and amino acid changes rat hrain during maturation. Am. J. Phystol. 21)3: 748 (1962)

35. Widdowson. 1: M: (hemical composition of newly born animals. Nat (l.ond.). 100: $626(1950)$

36. Widdowson. E. M : Cirouth and composition of the fetus and newborn. In: N Assali: Biology of Gestation. p. 149 (Academic Press. Inc.. New York. 197

37. Widdoweon I. M and Dickerson. J W T ( hemical composition of the hun hody. In: C I Comar. F. Bronner Mineral Metaholism. Vol. 2. Parl A. (Academic Press. Inc. New York. 1964)

38. Widdouson. E. M.. and Spray. ( . M.: (hemical development in utero. Arch. (hild. 20: 205 (1951).

34. Williams, J. Hirsch. N. J. Corbet. A. J. S. and Rudolph. A. J.. Postnatal h shrinkage in small infants. Pediatrics. 59: 619 (1977).

40. The present address of Dr. David M. Coulter is: Boston Prenatal (enter. Harrison Avenue. Boston. MA (1)2118

41. The authors thank I)r. H. William Taeusch. Director. Joint Program in N natology. for his encouragement and support during this research and for thoughtiul review of the manuscript. Dr. (lement A. Smith also provi helpful suggestions during its preparation.

42. Reyuests for reprints should he addressed to: David M. (onlter. M.I).. Bo. Perinatal (enter. XIX Harrison Avenue. Boston. MA (121IX (L!SA).

43. Received for publication February 7. 1979

44. Accepted for publication January 14. 19811. 